\title{
Psicodinâmica e saúde mental do trabalhador de enfermagem: ritmo acelerado e intensificação do fazer*
}

\author{
Recebido em: 06/05/2010
}

Aceito em: 09/12/2010

O presente estudo discute a psicodinâmica do trabalho da enfermagem em urgência e emergência e sua repercussão na saúde mental do trabalhador,

a partir de pesquisa qualitativa que focou o labor da equipe de enfermagem de um serviço público de pronto-socorro. Foram realizadas análises de documentos, observações não participantes e entrevistas semiestruturadas com os trabalhadores. Todos os preceitos éticos foram atendidos e as informações coletadas, submetidas à análise de conteúdo. Os resultados apontam a presença de um ritmo de trabalho intensificado e caracterizado pela imprevisibilidade, gerando consequências no cotidiano e na saúde mental do trabalhador.

Descritores: Saúde do Trabalhador, Saúde Mental, Condições de Trabalho, Enfermagem em Emergência.

\section{Psychodynamics and mental health of nursing workers: pace and intensification of doing}

This study discusses the psychodynamics of work of nursing in emergency care and its impact on the mental health worker, from qualitative research that focused on the work of the nursing team of a public emergency room. It was carried out analysis of documents, non participating observations and semi structured interviews with workers. All ethical guidelines were met and the informations were collected were subjected to content analysis. The results indicate the presence of an intensified work pace and characterized by unpredictability, creating consequences in everyday life and the mental health worker.

Descriptors: Occupational Health, Mental Health, Working Conditions, Emergency Nursing.

\section{La psicoterapia y la salud mental de los trabajadores de enfermería: incrementar el ritmo e intensificación del hacer}

Este trabajo discute la psicodinámica del trabajo de enfermería en la atención de emergencia y su impacto en la salud mental del trabajador, a partir de la investigación cualitativa que se centró en el trabajo del equipo de enfermería de un servicio público de atención de emergencia. Fueron realizadas análisis de los documentos, observaciones no participantes y entrevistas semiestructuradas con los trabajadores. Todas las recomendaciones éticas fueron recibidas y las informaciones recogidas se sometieron a análisis de contenido. Los resultados indican la presencia de un ritmo de trabajo intensificado y caracterizado por la imprevisibilidad, generando consecuencias en la vida cotidiana y en la salud mental del trabajador.

Descriptores: Salud Ocupacional, Salud Mental, Las Condiciones de Trabajo, Emergencia de Enfermería.

\section{INTRODUÇÅO}

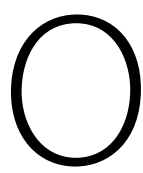

s serviços de pronto-socorro contemporâneos contêm uma especificidade que os distingue de quaisquer outros serviços de saúde ${ }^{(1)}$, uma vez que a organização do trabalho se encontra baseada no agir imediato, dependente do tempo e guiado pelo objetivo de salvar a vida. Assim, no cotidiano dos serviços de urgência e emergência, o ritmo de trabalho é imprevisível quanto ao número de pacientes que necessitam de cuidados imediatos e, ainda, quanto à aceleração exigida.

Esses aspectos definem as características peculiares da organização no contexto das emergências e, consequentemente, da repercussão dessa à saúde dos trabalhadores ali inseridos. Para a psicodinâmica do trabalho, pensar sobre a organização requer considerar a variável distância entre a organização prescrita para o trabalho e sua real organização, ou seja, o espaço existente entre aquilo que é preconcebido para uma determinada atividade e as ações que configuram o trabalho em ato(2).

A partir desse direcionamento, a organização e suas repercussões para a saúde do trabalhador podem ser compreendidas tendo em vista o quanto seria difícil antecipar todas as situações reais do universo do trabalho,

\footnotetext{
1 Docente Assistente da Faculdade de Enfermagem da UFPel. Doutoranda do Programa de Pós-Graduação em Enfermagem (PPGEnf) da UFRGS. Integrante do Giso/UFRGS. E-mail: daiadalpai@yahoo.com.br.

2 Docente Associada da Escola de Enfermagem da UFRGS. Doutora e Docente Permanente do PPGEnf/UFRGS. Líder do Giso/UFRGS. E-mail: lila@enf.ufrgs.br. 3 Docente e Coordenador do Curso de Psicologia das Faculdades Integradas de Taquara (Faccat). Doutorando do Programa de Pós-Graduação em Psicologia (PPGPsico) da UFRGS. E-mail: jeffsilkrug@yahoo.com.br.

* Elaborado a partir da dissertação de mestrado Enfermagem, Trabalho e Saúde: Cenas e Atores de um Serviço Público de Pronto-Socorro, apresentada ao programa de pós-graduação em enfermagem da Universidade Federal do Rio Grande do Sul (UFRGS), Porto Alegre (RS), Brasil.
} 
sendo impossível prever o percurso exato da produção e, portanto, prescrever com exatidão o trabalho nessa área. Dessa forma, o trabalho prescrito é insuficiente para responder à realidade da produção, já que essa resulta das relações intersubjetivas e sociais nesse ambiente ${ }^{(3)}$. Assim, as relações sociais ajustam o que é prescrito para o trabalho, transformando-o em modos operatórios reais. Diante disso, acredita-se que o que está prescrito nunca é suficiente e todo trabalho é sempre de concepção. Assim, o trabalho é humano por definição, já que sua existência se encontra onde a ordem tecnológica-maquinal é insuficiente ${ }^{(3)}$.

Pensar o trabalho dessa forma aponta a necessidade de considerarmos a busca constante do trabalhador por uma margem para a concepção em seu labor. Entretanto, o ajustamento entre aquilo que está previsto como tarefa a ser desempenhada e os modos operatórios reais depende do reconhecimento do direito dos trabalhadores de investir nesse espaço como meio potencial para o uso da inteligência na concepção do trabalho ${ }^{(4)}$.

Tendo isso em vista, o presente estudo focaliza a psicodinâmica do trabalho da enfermagem em um serviço de urgência e emergência, a fim de compreender o trabalho real nesse espaço e, consequentemente, a saúde mental dos trabalhadores.

\section{METODOLOGIA}

Trata-se de um estudo descritivo, de abordagem qualitativa, realizado junto a um hospital público de pronto-socorro de Porto Alegre, RS.

As técnicas de coleta de dados utilizadas foram, respectivamente: (a) análise de documentos e registros da instituição a fim de auxiliar na compreensão do contexto organizacional no qual as atividades da enfermagem estiveram inseridas; (b) 14 períodos de observação nãoparticipante sobre as interações laborais da enfermagem, as quais foram registradas em diários de campo, com duração média de duas horas em cada período, tendo como objetivo apreender aspectos do trabalho em cena; e (c) 12 entrevistas semiestruturadas com trabalhadores de enfermagem (enfermeiros, técnicos e auxiliares), as quais almejavam conhecer o sentido atribuído pelas vivências nesse âmbito.

Quanto à seleção dos participantes, toda a equipe de enfermagem foi contemplada na observação, sendo que, para as entrevistas, os sujeitos foram selecionados intencionalmente entre os profissionais que representassem os melhores informantes, de acordo com as exigências do estudo. As entrevistas foram realizadas no próprio local de trabalho, mediante agendamento prévio e em local apropriado para a manutenção da privacidade dos envolvidos.

As prerrogativas éticas foram atendidas com o uso do Termo de Consentimento Livre e Esclarecido e Termo de Responsabilidade pelo Uso dos Dados. Diante disso, assegurou-se a responsabilidade com as informações recebidas e o anonimato, atentando-se, ainda, para a autorização para a gravação da entrevista em áudio. $\mathrm{O}$ projeto de pesquisa foi avaliado e aprovado pelo Comitê de Ética em Pesquisa da Instituição na qual a coleta de dados foi realizada, sob o número AC CP N.022/2005.

As informações oriundas da coleta foram reunidas, organizadas e analisadas com base no conjunto de instrumentos metodológicos da Análise de Conteúdo(5), dando origem aos conjuntos interpretativos relacionados ao ritmo laboral acelerado e à intensificação do trabalho e suas consequências para a saúde mental do trabalhador.

\section{APRESENTAÇÃO E DISCUSSÃO DOS RESULTADOS}

A fim de facilitar a apresentação dos resultados, esta seção foi subdividida a partir dos conjuntos interpretativos mais significativos. Além disso, são classificados com a letra "E" os trechos das entrevistas e com a letra "O" os trechos das observações, assim escolhidos para exemplificar e significar a discussão.

Ritmo laboral acelerado: o imprevisível e a necessidade de "fazer a coisa fluir"

Os resultados encontrados reafirmam, no ambiente estudado, o "ritmo frenético da prática de emergência" de estudo(1) que focou o cotidiano de profissionais da emergência.

"É um trabalho muito dinâmico, tu trabalhas atendendo, olhando o que tu estás atendendo, sempre com o olho voltado para trás, porque a porta de entrada está aberta e então tu não trabalhas com um ritmo fixo predeterminado; tem tantos leitos, tantos pacientes, e deu. Então acontece tudo ao mesmo tempo." (E12)

"É um trabalho que não tem uma rotina, não tem uma sistemática de dizer que funciona assim. Cada caso é um caso, cada dia é um dia, cada plantão é mais diferenciado do que o outro, tem plantões que às vezes são mais calmos, tem plantões que parece que vão ser calmos e viram um caos!" (E6)

No trabalho em emergência, o quadro temporal é marcado pelo tempo do relógio, pelo ritmo da demanda dos usuários e pela jornada de trabalho. Além da exigência de pontualidade e regularidade, existe uma pressão pela rapidez na realização das atividades que estão relacionadas à 
alta demanda de trabalho e à corrida em benefício da vida ${ }^{(6)}$.

Lidar com o inesperado faz parte do cotidiano dos serviços de pronto-socorro. Entretanto, em alguns momentos, os trabalhadores podem permanecer, por exemplo, algumas horas sem que haja atendimento na sala de emergência, o que caracteriza o ritmo de trabalho como imprevisível, ou seja, a distribuição dos atendimentos, no tempo, não é constante.

"Na madrugada, o que é que a gente faz? A gente senta ali, se a sala estiver vazia, tu ficas sentada, a qualquer momento aquela porta abre e a gente sai correndo para atender o paciente." (E7)

O que pode surgir "daquela porta" é a questão que orienta a atenção permanente da equipe de enfermagem. A complexidade e a quantidade de casos que podem dar entrada na sala são fatores que determinam a prioridade dada à agilidade nas ações do cuidado. $\mathrm{O}$ objetivo do serviço é realizar o primeiro atendimento, ou seja, estabilizar hemodinamicamente o paciente e encaminhá-lo aos setores que deem a continuidade necessária ou então liberá-lo.

"Se tiver um tiroteio em algum lugar, eu estarei com três baleados ao mesmo tempo, pode acontecer, já teve [...] então se tu sabes que tem isso, tu tens que fazer a coisa fluir!" (E12)

"Se o fluxo não anda, se os pacientes não são liberados, se os pacientes que têm que ir para a cardio não vão, se os pacientes que têm que fazer exames não vão, se os pacientes que têm que ser internados não vão, vai acumulando gente dentro da sala e vai acabar num ponto que tu não consegues dar conta do serviço, que tu não consegues ver os outros pacientes, que tu não consegues saber quem é o grave e quem não é, entendeu? Tem muita gente para observar ao mesmo tempo!" (E5)

"Fazer a coisa fluir" representa a necessidade de agilizar as etapas que permitem o encaminhamento do paciente, ou seja, agilizar o suporte avançado de vida, os pedidos de exames e sua realização, a avaliação dos mesmos e a tomada de decisão quanto ao destino do paciente. Por outro lado, esse "fluir" também pode ser entendido como a necessidade do trabalhador de manter em trânsito constante as emoções despertadas pelo contato com a complexidade das situações vividas, não havendo espaço para representar essa "coisa" em sua mente, pois isso impediria a ação terapêutica emergencial exigida pelo caso.

Embora todas essas ações também dependam da agilidade da enfermagem, é nas mãos do médico que estão as decisões quanto à realização de exames, procedimentos e condutas terapêuticas, assim como a permanência do paciente em observação, encaminhamento para uma UTI ou enfermaria ou liberação. Dessa forma, na tentativa de "fazer a coisa fluir", a enfermagem, por vezes, confronta a hegemonia médica nos serviços de emergência.

Assim, pode-se dizer que questões como o ritmo de trabalho imprevisível e necessidade de constante fluxo de pacientes estão implicadas na configuração das redes estruturais que organizam e determinam a prática da enfermagem nos serviços de urgência e emergência. A fim de discuti-las, aborda-se as consequências da intensificação do trabalho.

\section{Intensificação do trabalho e suas consequências para a saúde mental do trabalhador}

"Fazer a coisa fluir" depende, também, da disponibilidade de leito para a transferência do paciente para outras unidades do hospital ou mesmo outras instituições da cidade. Por isso, muitas vezes, os pacientes permanecem na sala de emergência por longo tempo, o que modifica a organização do trabalho da enfermagem nesse setor.

"Nós somos, na verdade, socorristas de emergência, que é para dar o primeiro atendimento e passar adiante, só que isso não vem acontecendo. A gente dá o primeiro atendimento, a gente prepara o paciente e a gente fica atendendo o paciente na sala, vai fazer o papel de intensivista, que é o controle do paciente que está internado ali!" (E7)

Diante da necessidade de atender os pacientes que precisam de cuidados contínuos, a enfermagem desenvolveu uma organização própria para incluir esses atendimentos. Faz-se uma escala com horários preestabelecidos para cada auxiliar/técnica a fim de atender às necessidades de cuidados intensivos ao paciente internado.

Trata-se, portanto, de estratégia utilizada diante da necessidade instituída pela organização e condições de trabalho, acabando por modificar o papel e a prescrição original do trabalho do profissional. Essa alteração de função incide, ainda, sobre a identidade e a saúde mental desses trabalhadores ${ }^{(7)}$, o que exige que os profissionais envolvidos redefinam laboralmente suas formas de operar no trabalho e, portanto, de "ser" trabalhador de enfermagem.

Acrescenta-se a isso o fato de que cada uma das funções (socorristas de emergência e intensivistas) pressupõe diferentes disponibilidades psicológicas do trabalhador. No atendimento intensivo, por exemplo, percebe-se a exigência de vínculos mais duradouros e empáticos entre o profissional e o paciente, inclusive entendendo essa disponibilidade como instrumento de cuidado por se tratar de um contato mais prolongado. Exigir de um socorrista essa mesma disponibilidade emocional, ao mesmo tempo que ele necessita exercer sua atividade de atender à emergência, passa a ser nocivo para a saúde do trabalhador. Essa exigência de outras finalidades para o trabalho em 
serviços de emergência também foi apontada em outro estudo sob a perspectiva das consequências disso para a qualidade do cuidado prestado ${ }^{(8)}$.

Percebeu-se que a configuração do labor no serviço estudado tem exigido a intensificação do trabalho da enfermagem, o que reflete negativamente na saúde emocional do trabalhador.

"Um dia eu cheguei, tinha três pacientes internados, e eu que estava na escala de pacientes. Eu olhei para a enfermeira e disse assim: 'Enfermeira, eu estou com três pacientes internados entubados. Um auxiliar de enfermagem na CTI fica com três pacientes entubados?" (E7)

A situação remete ao que é descrito na literatura ${ }^{(9)}$ sobre as formas de consumo da força de trabalho. É nesse nível que estão implicadas as diversas formas de desgaste do trabalhador, as quais podem ocorrer de duas maneiras: pela intensificação do trabalho ou pelo aumento da produtividade, por meio de uma mudança na organização do trabalho.

No caso estudado, trata-se da intensificação do trabalho derivada da falta de suporte do próprio hospital e do sistema de saúde do município para absorver a demanda que permanece na sala de emergência por mais tempo do que o previsto. Além disso, na percepção das participantes do estudo, a falta de protocolos para os atendimentos tem feito com que haja intervenções desnecessárias, sobrecarregando os trabalhadores.

"Tu estás vendo que o sistema não está funcionando... Não tem protocolo

para atendimento de AVC, não tem para paciente de IAM, não tem nada, aí cada médico faz o que quer [...] exames são pedidos duas vezes, é falta de comunicação, é falta de ter um protocolo [...]. A situação é bem desorganizada, acontece que um médico não libera paciente do outro, fica acumulando, cada um tem uma maneira de trabalho, quando não tem rotina cada um faz da sua maneira, isso gera transtornos e não libera os pacientes." (E8)

Por meio da Política Nacional de Humanização, o Ministério da Saúde tem incentivado mudanças estruturais de gestão e atenção em saúde a fim de avançar em prol do acolhimento e da resolução com base em protocolos clínicos e estabelecimento de fluxos para que sejam eliminadas as intervenções desnecessárias. Embora o hospital em questão esteja buscando a implementação dessa política, os atuais processos adotados desqualificam a atenção prestada pelo serviço e ainda contribuem para a intensificação do trabalho e o sofrimento dos profissionais que atuam na promoção e recuperação da saúde ${ }^{(10)}$

Ainda foi possível constatar que, mesmo que as salas estejam lotadas, o serviço continua recebendo os pacientes, como pode ser visto no trecho que segue.

"Vai empilhando boletim e tu tens que atender! Tu és obrigado a dar conta!" (E8)

Estudo $^{(1)}$ de dois serviços públicos de emergência do Rio de Janeiro trouxe à tona a questão do sofrimento dos profissionais na intensificação do trabalho para dar conta da lotação, que excede a capacidade do setor de emergência. Assim, sob essas condições de trabalho, pode-se verificar que os funcionários se veem impedidos de cumprir corretamente suas funções, o que pode gerar sofrimento. Isso é chamado de "pressão para trabalhar mal"(4) e classificado como violência $^{(6)}$ pela limitação em proporcionar assistência de qualidade.

Essa intensificação, porém, é imprevista e inconstante, ao passo que a escala de trabalho obedece a uma distribuição uniforme dos profissionais, conforme pode ser constatado na análise documental. No entanto, no decorrer do plantão, a alternativa utilizada para dar conta da intensificação do trabalho é a redistribuição das pessoas entre as salas do serviço a fim de atender ao local que mais necessitar.

Essa situação foi observada com maior frequência na sala de emergência, onde, entre os cinco trabalhadores de nível médio escalados para cada turno de trabalho, exige pelo menos um para atender os pacientes internados. Dessa forma, restarão quatro profissionais para os atendimentos de emergência, os quais precisam atuar simultaneamente nas manobras de suporte ao trauma.

"Um paciente é trazido à sala em uma maca empurrada por auxiliares de enfermagem do serviço. A residente: 'É tiro?'. O auxiliar do transporte: 'Parece que é uma overdose, ele foi trazido pela brigada.' Três auxiliares/técnicas de enfermagem se aproximam. Logo é detectada a parada cardiorrespiratória. A residente solicita a presença do outro residente e, além desse, se aproximam a médica, um interno, outra auxiliar/ técnica e a enfermeira. As manobras se iniciam com todos concentrados na tarefa, enquanto apenas uma auxiliar/ técnica se ocupa em atividades que não se relacionam ao atendimento à parada cardiorrespiratória." (09)

Constata-se, portanto, que a rotina de trabalho em emergência exige um constante estado de tensão e vigília do trabalhador, uma vez que esse pode ser requisitado a qualquer momento a deixar a tarefa que está realizando para ser inserido em um procedimento de cuidado especializado, que representa a vida ou a morte do paciente. Frente a isso, os profissionais de enfermagem sofrem com sentimentos como cansaço, esgotamento, angústia e revolta pela sobrecarga e limitações dos recursos frente às situações que envolvem risco de morte. Dessa forma, pode-se inferir que essa realidade é geradora 
de estados emocionais caracterizados pela vivência constante de ansiedade, trazendo prejuízos à saúde mental do trabalhador por meio do desgaste emocional e de transtornos mentais graves ${ }^{(11)}$.

Para se defender de situações danosas, os profissionais adotam estratégias de enfrentamento. Essas, por sua vez, têm sido constituídas pelo distanciamento emocional frente à morte e a despersonalização do cuidado evidenciada através da frieza ou humor em suas atitudes no trabalho ${ }^{(12,13)}$.

$O$ trecho a seguir descreve uma das inúmeras situações que mobilizam a equipe de saúde para a tomada de decisões quanto às prioridades no atendimento, o que também contribui para a tensão a ser modulada a fim de não adoecer.

"Uma funcionária do Samu e mais um auxiliar de enfermagem do serviço trazem uma maca com uma vítima de trauma para dentro da sala de emergência. São passadas informações para o residente, enquanto a médica $e$ os internos se aproximam. A avaliação médica se inicia, enquanto um técnico de enfermagem prepara materiais necessários para verificar sinais vitais e complementar a avaliação. Nesse momento, entra um novo caso, proveniente de acidente de trânsito e trazido por outro serviço pré-hospitalar, que logo recebe a atenção da equipe médica e de enfermagem, que deixam o atendimento anterior para dar atenção ao caso mais grave, o segundo $a$ entrar. $O$ paciente avaliado como de menor gravidade é levado a outro setor." (013)

Levar o paciente para outra sala nem sempre é possível, pois a gravidade dos casos, por vezes, não permite essa opção, uma vez que somente a sala de emergência está equipada para esses atendimentos. Nessas circunstâncias, a enfermagem vivencia o dilema de escolher a quem prestar $o$ atendimento.

"A enfermeira conversa com uma técnica/auxiliar na sala de urgências clínicas; elas falam sobre a sala de emergência: 'Ontem não tinha mais nenhum lugar lá, para nenhuma maca. Sorte que aquele cara morreu, porque nós não tínhamos mais respirador no hospital.'" (O4)

As rotinas de trabalho em emergência afetam tão intensamente as emoções dos profissionais que esses, muitas vezes, chegam a relatar o "desejo" de morte de um paciente a fim de poderem estar mais disponíveis para os cuidados de um doente com maiores chances de vida. Aspectos relacionados a esse fenômeno também foram apontados em estudo(14) que discutiu a vivência da escolha como um fator gerador de sofrimento por parte dos profissionais da emergência. A mediação entre os mais variados dramas, a estrutura e a distribuição dos recursos e serviços fazem com que esses profissionais tenham de decidir, muitas vezes, quem deve morrer e quem deve viver ${ }^{(14: 87)}$.
Outro aspecto relativo à psicodinâmica do trabalho em emergência observado durante a coleta de dados foi que, além da equipe médica e de enfermagem, outras personagens participam do processo de trabalho. Nesse sentido, contatou-se que o segurança permaneceu a maior parte de seu tempo dentro da sala de atendimentos, interagindo diretamente com a equipe de saúde e ajudando a "fazer a coisa fluir". Essa personagem atua fazendo a interlocução entre os que estavam fora e os que permaneciam dentro da sala, ou seja, pacientes, familiares e equipe de saúde. Ele ainda realiza o controle da porta, avaliando a possibilidade de entrada de familiares, assim como a entrada dos próprios pacientes para serem atendidos quando, a partir de sua avaliação, representarem casos que não podem mais esperar.

Como evidenciado pela psicodinâmica do trabalho, embora o sofrimento seja da ordem do singular, sua solução é coletiva ${ }^{(15)}$. Dessa forma, o

segurança torna-se protagonista nas cenas decisivas para a rapidez no atendimento prestado, ainda que, na avaliação da enfermagem, ele também possa ser o culpado pela superlotação da sala, uma vez que sua atuação excederia ao que a ele fora prescrito.

"Um senhor entra na sala, acompanhado pelo segurança, e vai até um paciente que está sendo atendido. A auxiliar questiona a presença daquele homem e o segurança justifica que ele veio pegar um objeto com o paciente. Quando o segurança sai, a auxiliar comenta: 'Esses guardas... só botam gente para dentro e não ficam na porta." (06)

"Botar gente para dentro" representa ter de intensificar a carga e o ritmo de trabalho para atender um maior número de pacientes e, por vezes, encontra-se na figura do "guarda" um culpado pela situação a fim de dar vazão à tensão vivida.

Além disso, a situação interfere nos parâmetros usados para classificar a gravidade dos casos e, portanto, nas decisões sobre a ocupação ou não de uma vaga na sala de emergência. Surge, então, o chamado "caso frio", classificado pelos trabalhadores como não urgente, ou o " $\mathrm{H}$ ", expressão frequentemente adotada para se referir a pacientes com pretensos sintomas histéricos.

"A coisa não anda! Um monte de paciente... às vezes um paciente grave que está aguardando, por quê? Porque tem um monte de paciente que não precisava estar aqui!" (E8) "Às vezes tu tens... no meio da diversidade, no meio da quantidade de pacientes, no meio de vários casos, chega unha encravada, ' $H$ ' infectado com florzinhas, mas tem aquele paciente que pode estar infartando [...]. Às vezes cento e poucos pacientes numa noite, e no meio de tantos um ou outro é um caso especial." (E6)

Esses relatos vão ao encontro de outro estudo(1) que 
apontou o sentimento de contrariedade experimentado pelos profissionais de enfermagem diante dos pacientes que "não são de seu setor", pois se veem obrigados a se desdobrarem a fim de atender tantos indivíduos que não são casos de urgência ou emergência. Segundo o estudo ${ }^{(1: 65)}$, além da evidente sobrecarga de trabalho, esses pacientes não motivam o profissional de enfermagem, uma vez que não exigem dele conhecimento específico de urgência/emergência. Na mesma direção, outra pesquisa ${ }^{(8)}$ mostrou que a equipe de saúde revela insatisfação com a procura excessiva de pacientes, cujas necessidades não podem ser classificadas como urgência ou emergência, apontando o número de atendimentos como justificativa para a resistência em realizar o trabalho e o descompromisso com a produção do cuidado.

\section{CONSIDERAÇÕES FINAIS}

Os resultados do presente estudo sugerem que a psicodinâmica do trabalho da enfermagem em setor

"A equipe de saúde revela insatisfação com

a procura excessiva de pacientes, cujas necessidades não podem ser classificadas

como urgência ou
emergência"

excessos ao que é prescrito vivenciados com angústia e insegurança. Evidenciou-se, portanto, que são necessárias aos trabalhadores oportunidades para refletir sobre seu trabalho a fim de proteger sua saúde mental e a qualidade do serviço ofertado.

Sabe-se que o trabalho possui caráter central na estruturação do sujeito e, por isso, cria-se a hipótese de que haja ainda repercussões dessas vivências de trabalho fora do ambiente laboral, fato não aprofundado no presente estudo. A organização do trabalho, dessa forma, poderia repercutir na saúde mental do trabalhador de maneira a limitar a aproximação afetiva com as pessoas de suas relações, empobrecendo a capacidade de representação das tensões vivenciadas, prejudicando, assim, sua condição de pensar seus sentimentos em vez de atuálos apenas com vistas a questões práticas e emergenciais, como simples descarga de tensão, "fazendo a coisa fluir".

Por fim, reitera que, como defendido na literatura, a psicodinâmica do trabalho auxilia a preencher lacunas epistemológicas importantes no conhecimento em saúde e sua relação com o trabalho, permitindo ampliar o olhar e a escuta aos fenômenos ligados à saúde mental dos trabalhadores.

\section{Referências}

1. Deslandes SF. Frágeis deuses: profissionais de emergência entre os danos da violência e a recriação da vida. Rio de Janeiro: Fiocruz; 2002.

2. Jacques MG, Codo W. Saúde mental e trabalho: leituras. Petrópolis:

Vozes; 2002.

3. Lancman S, Sznelwar LI. Christophe Dejours: da psicopatologia à

psicodinâmica do trabalho. Rio de Janeiro: Fiocruz, Brasília: Paralelo 15; 2004.

4. Dejours C. A banalizaçāo da injustiça social. Rio de Janeiro: Ed. FGV; 1999.

5. Bardin L. Análise de conteúdo. Lisboa: Edições 70; 2009.

6. Costa ALRC. As múltiplas formas de violência no trabalho de enfermagem: o

cotidiano de trabalho no setor de urgência e emergência clínica em um hospital público [tese]. Ribeirão Preto (SP): Escola de Enfermagem de Ribeirão Preto da USP; 2005.

7. Dal Pai D, Lautert L. Work under urgency and emergency and its relation with the health of nursing professionals. Rev Latinoam Enferm. 2008;16(3):439-44. 8. Garlet ER, Lima MADS, Santos JLG, Marques GQ. Finalidade do trabalho em urgências e emergências: concepções de profissionais. Rev Latinoam Enferm. 2009;17(4):535-40.

9. Laurell AC, Noriega Elio M, López Arellano O, Martínez Alcántara S. El trabajo como determinante de la enfermedad. Cuad Méd Soc. 1991;56:17-33. 10. Dal Pai $D$, Lautert L. Sofrimento no trabalho de enfermagem: reflexos do "discurso vazio" no acolhimento com classificação de risco. Esc Anna Nery Rev Enferm. (No prelo 2011).

11. Salomé GM, Martins MFMS, Espósito VHC. Sentimentos vivenciados pelos profissionais de enfermagem que atuam em unidade de emergência. Rev Bras Enferm. 2009;62(6):856-62.

12. Dal Pai $D$, Lautert L. Estratégias de enfrentamento do adoecimento: um estudo sobre o trabalho da enfermagem. Acta Paul Enferm. 2009;22(1):60-5. 13. Monteiro JK. Organização do trabalho e sofrimento psíquico de trabalhadores da saúde. In: Mendes AM, Merlo ARC, Morrone CF, Facas EP, organizadores. Psicodinâmica e clínica do trabalho: temas, interfaces e casos brasileiros. Curitiba: Juruá Ed.; 2010. p. 335-45.

14. Skaba, MMVF. O vício da adrenalina: etnografia da violência num hospital de emergência [dissertação]. Rio de Janeiro (RJ): Escola Nacional de Saúde Pública da Fundaçăo Osvaldo Cruz; 1997.

15. Lancman S, Uchida S. Trabalho e subjetividade: o olhar da psicodinâmica do trabalho. Cad Psicol Soc Trab. 2003;6(1):79-90. 